\title{
Performance of Predictive Equations Specifically Developed to Estimate Resting Energy Expenditure in Ventilated Critically III Children
}

\author{
Corinne Jotterand Chaparro, PhD ${ }^{1,2}$, Patrick Taffé, $\mathrm{PhD}^{3}$, Clémence Moullet, BSc ${ }^{1}$, Jocelyne Laure Depeyre, BSc ${ }^{1}$, \\ David Longchamp, MD², Marie-Hélène Perez, $\mathrm{MD}^{2}$, and Jacques Cotting, MD²
}

\begin{abstract}
Objective To determine, based on indirect calorimetry measurements, the biases of predictive equations specifically developed recently for estimating resting energy expenditure (REE) in ventilated critically ill children, or developed for healthy populations but used in critically ill children.

Study design A secondary analysis study was performed using our data on REE measured in a previous prospective study on protein and energy needs in pediatric intensive care unit. We included 75 ventilated critically ill children (median age, 21 months) in whom 407 indirect calorimetry measurements were performed. Fifteen predictive equations were used to estimate REE: the equations of White, Meyer, Mehta, Schofield, Henry, the World Health Organization, Fleisch, and Harris-Benedict and the tables of Talbot. Their differential and proportional biases (with 95\% Cls) were computed and the bias plotted in graphs. The Bland-Altman method was also used.

Results Most equations underestimated and overestimated REE between 200 and $1000 \mathrm{kcal} /$ day. The equations of Mehta, Schofield, and Henry and the tables of Talbot had a bias $\leq 10 \%$, but the $95 \% \mathrm{Cl}$ was large and contained values by far beyond $\pm 10 \%$ for low REE values. Other specific equations for critically ill children had even wider biases.

Conclusions In ventilated critically ill children, none of the predictive equations tested met the performance criteria for the entire range of REE between 200 and $1000 \mathrm{kcal} /$ day. Even the equations with the smallest bias may entail a risk of underfeeding or overfeeding, especially in the youngest children. Indirect calorimetry measurement must be preferred. (J Pediatr 2017; $\square: \square-\square$ (ם).
\end{abstract}

\section{See editorial, p coe}

$\mathrm{n}$ critically ill children, maintaining a caloric intake close to the energy need will improve recovery. ${ }^{1}$ Scientific societies recommend measuring resting energy expenditure (REE) by indirect calorimetry as the gold standard method, especially in children with malnutrition or suspected altered metabolism. ${ }^{1,2}$ Nevertheless, recent studies have shown that REE is measured in a minority of pediatric intensive care units (PICUs). ${ }^{3-6}$ PICUs face an additional difficulty in that the sole device currently validated for use in critically ill patients— the Deltatrac II calorimeter (Datex-Ohmeda, Helsinki, Finland) ${ }^{7,8}$ —is no longer being manufactured.

In the absence of indirect calorimetry measurements, current guidelines propose estimating REE with predictive equations while highlighting that the available equations lack precision, but they do not offer advice on which equations to use. ${ }^{1,2}$ Worldwide and European surveys ${ }^{5,6}$ have shown that in most PICUs, REE is estimated using the common predictive equations of Schofield ${ }^{9}$ and the World Health Organization, ${ }^{10}$ which were developed for use in healthy children. Specific equations for critically ill children have been designed. ${ }^{11-13}$ Several studies have concluded that the equations of White lack precision, however. ${ }^{12,14-17} \mathrm{Al}-$ though Meyer et al ${ }^{12}$ developed 3 new predictive equations using diagnostic categories, the validity of these equations has not yet been evaluated. In 2015, Mehta et a ${ }^{13}$ designed an equation using measured carbon dioxide production $\left(\mathrm{VCO}_{2}\right)$ and a fixed respiratory quotient $(\mathrm{RQ})$ of 0.89 . A recent study conducted in children after cardiopulmonary bypass identified RQ as the most important determinant of the bias with the $\mathrm{VCO}_{2}$-based equation. ${ }^{18}$ Kerklaan et $\mathrm{al}^{19}$ demonstrated that REE estimated with the equation of Mehta, ${ }^{13}$ using $\mathrm{VCO}_{2}$ measured by a SERVO-i ventilator with a Capnostat III sensor, was not sufficiently accurate for children weighing $<15 \mathrm{~kg}$. We hypothesized that some available predictive equations should not be used in ventilated critically ill children. Therefore, the objective of this study was to determine, based on indirect calorimetry measurements, the biases

\begin{tabular}{|llll|}
\hline LoA & Limits of agreement & $\mathrm{REE}$ & Resting energy expenditure \\
MEE & Measured energy expenditure & $\mathrm{RQ}$ & Respiratory quotient \\
PICU & Pediatric intensive care unit & $\mathrm{VCO}_{2}$ & Carbon dioxide production \\
\hline
\end{tabular}

From the ${ }^{1}$ Department of Nutrition and Dietetics, School of Health Professions, University of Applied Sciences Western Switzerland, Geneva 1227, Switzerland; 2Pediatric Intensive Care Unit, Medico-Surgical Department of Pediatrics, University Hospital of Lausanne, Lausanne 1011, Switzerland; and ${ }^{3}$ Institute of Social and Preventive Medicine, Lausanne 1010, Switzerland

Partially funded by the DORE Funds of the Swiss National Science Foundation (13DPD3-114074 2) and the Marisa Sophie Foundation. The authors declare no conflicts of interest.

0022-3476/\$ - see front matter. @ 2016 Elsevier Inc. All rights reserved.

http://dx.doi.org10.1016/j.jpeds.2016.12.063 
of predictive equations developed specifically for ventilated critically ill children or developed for a healthy population but frequently used in the PICU.

\section{Methods}

This secondary analysis study used our data on REE measured by indirect calorimetry in ventilated critically ill children in a prospective study on protein and energy needs performed in the PICU of the University Hospital of Lausanne, Switzerland. ${ }^{20}$ All children (from birth to age 16 years) admitted to the PICU between January 2008 and April 2010 were eligible for inclusion in the study if they had an expected duration of mechanical ventilation $\geq 72$ hours. Exclusion criteria were as follows: fraction of inspired oxygen $>60 \%$, an air leak around the endotracheal tube $>10 \%$, chylothorax, chronic or acute renal disease, severe loss of inflammatory fluid through a pleural or peritoneal drain, exudative enteropathy, therapeutic hypothermia, birth weight $<2.5 \mathrm{~kg}$, and gestational age $<36$ weeks. The protocol and study were approved by the Ethics Committee of the University Hospital of Lausanne. Written informed consent was obtained from the parents of all included patients.

\section{Indirect Calorimetry Measurements}

Measurements of REE by indirect calorimetry (Deltatrac II) and of total urinary nitrogen by chemoluminescence (Antek 7000 analyzer; Antek, Houston, Texas) ${ }^{21}$ were obtained daily from admission until extubation. The calorimeter was calibrated monthly using the ethanol-burn technique, adapted for pediatric values. Before measurements, the calorimeter was preheated for 1 hour and calibrated using a reference gas mixture. Infants were ventilated with a Babylog ventilator (Dräger, Lübeck, Germany). Children weighing $>4 \mathrm{~kg}$ were ventilated with a Galiléo ventilator (Hamilton Medical, Bonaduz, Switzerland). REE was measured for at least 60 minutes, if possible at the same time each day during a quiet period without planned procedures. When an event occurred (change in fraction of inspired oxygen, physiotherapy, agitation or suctioning of the endotracheal tube), the measurement was interrupted, and then not resumed until at least 30 minutes later. REE was calculated using the modified Weir equation, ${ }^{22}$ which includes the measured total urinary nitrogen. The first 10 minutes of measurement were discarded to exclude artifacts. A steady state was defined as a coefficient of variation of $\mathrm{VCO}_{2} \leq 10 \%$ for at least 25 consecutive minutes. ${ }^{23}$ Steady state was not achieved for 5 measurements, which were not used for analysis.

\section{Predictive Equations to Estimate REE in Ventilated Critically III Children}

We predicted REE using equations specifically developed for ventilated critically ill children: the equations of White et al 1 and $2 ;^{11}$ Meyer et al A, B, and C; ${ }^{12}$ and Mehta et a ${ }^{13}$ (Table I; available at www.jpeds.com). In their respective studies, the authors compared predicted REE results with measured energy expenditure (MEE) values obtained with the Deltatrac II or the Vmax Encore instrument (Viasys Healthcare, Loma Linda,
California), using the Bland-Altman limits of agreement (LoA) method. ${ }^{24}$

\section{Predictive Equations to Estimate REE in Healthy Children and Adults}

We tested the performance of predictive equations or tables developed for healthy children and frequently used in critically ill children: the equations of Schofield with weight and height (Schofield WH), Schofield with weight (Schofield W), ${ }^{9}$ Henry with weight and height (Henry WH), Henry with weight (Henry W) ${ }^{25}$ the World Health Organization, ${ }^{10}$ Fleisch, ${ }^{26}$ HarrisBenedict, and Harris-Benedict for infants, ${ }^{27}$ and the tables of Talbot. ${ }^{28}$ In 2012, the European Food Safety Authority ${ }^{29}$ recommended the equations of Henry ${ }^{25}$ and Schofield ${ }^{9}$ in their guidelines for healthy children. The frequently used equations of Schofield are also presented in Table I. We also tested the equation of Harris-Benedict ${ }^{27}$ developed in adults but widely used in critically ill children.

\section{Statistical Analyses}

Traditionally, the Bland-Altman LoA methodology has been used to assess agreement between 2 methods of measurement. ${ }^{24,30}$ However, when variances of the measurement errors of the 2 methods differ, the LoA method can be misleading. ${ }^{31-34}$ Indeed, there are settings in which the regression line shows an upward or downward trend but there is no bias. In other cases, there is a bias despite a zero slope. ${ }^{32}$ To avoid these deficiencies, we performed our statistical analyses using a recently proposed methodology to assess differential and proportional biases. ${ }^{32}$

Based on individual repeated indirect calorimetry measurements (MEE, in kcal/day), this proposed statistical methodology allowed us to compute the true REE value for each child. ${ }^{32}$ Then the amount of the bias, which can be partitioned into a differential $(\alpha)$ and a proportional $(\beta)$ bias of the 15 predictive equations, was calculated with the following equation: bias $=(\alpha+\beta \times$ true_REE $)-$ true_REE..$^{32}$ The differential bias is an additive bias that occurs when a new measurement method produces values that are systematically lower than or above the reference standard $(\alpha \neq 0)$. The proportional bias is a multiplicative bias that occurs when the new measurement method produces values that are either lower or higher than the reference standard by an amount that depends on the level of the latent trait $(\beta \neq 1)$. For each equation, the percentage of bias with its $95 \%$ CI was calculated and plotted on a graph for comparing the performance of the different equations. A bias $\leq 10 \%$ was considered clinically acceptable. This low cutoff was chosen to avoid the risk of underestimation or overestimation of REE using the different equations. For describing equations in more detail, bias plots showing the bias as a function of the true REE, as well as the amounts of differential and proportional biases, are provided online with individual data for MEE. To allow comparisons with the available literature, the Bland-Altman mean bias and $\operatorname{LoA}^{24}$ (mean bias $\pm 1.96 \mathrm{SD}$ ) were calculated as well.

Characteristics of the population and MEE values are presented as median and IQR. Statistical analyses were 
performed using Stata 13.1 for Windows (StataCorp, College Station, Texas).

\section{Results}

Among a total of 449 PICU admissions, 78 children were eligible, and 3 parents refused their participation. Thus, the study group comprised 75 children ( 43 boys, 32 girls) with a median (IQR) age of 21 (5-35) months, most of whom were admitted to the PICU after surgery (73\%). The median Pediatric Risk of Mortality II score ${ }^{35}$ of children at PICU admission was 6 (IQR, 4-9), the median duration of mechanical ventilation was 6 (IQR, 4-8) days, and the median length of PICU stay was 11 (IQR, 7-16) days.

Based on $z$-scores of weight-for-height and height-for-age, ${ }^{36}$ $51 \%$ of children were of normal nutritional status, whereas $49 \%$ suffered from chronic and/or acute malnutrition. Seventyone infants (95\%) received exclusive continuous enteral nutrition introduced within 22 (IQR, 11-27) hours after admission. Patient characteristics are summarized in Table II.

A total of 407 indirect calorimetry measurements were performed, with a median of 6 (IQR, 3-7) measurements per patient. The median duration of the energy expenditure measurement was 90 (IQR, 75-114) minutes, and the median MEE was 501 (IQR, 322-648) kcal/day or 55 (IQR, 46-63) kcal/kg/ day. The median RQ was 0.83 (IQR, 0.80-0.89). The median $\mathrm{O}_{2}$ consumption was 8.0 (IQR, 6.8-9.2) $\mathrm{mL} / \mathrm{kg} /$ minute, and median $\mathrm{VCO}_{2}$ was 6.6 (IQR, 5.6-7.6) $\mathrm{mL} / \mathrm{kg} /$ minute. Median body temperature at the time of measurement was 36.9 (IQR, 36.6-37.4) ${ }^{\circ} \mathrm{C}$.

\section{Bias of the Predictive Equations}

The predictive equations varied strongly in performance and did not perform similarly over the entire range of MEE values. Most equations both underestimated and overestimated REE between 200 and $1000 \mathrm{kcal} /$ day (Table III).

The percentage of bias with its $95 \% \mathrm{CI}$ is presented for each predictive equation in Figures 1 and 2 to show the variation

\begin{tabular}{|lc|}
\hline \multicolumn{2}{|c|}{ Table II. Demographic and clinical variables ${ }^{*}$} \\
\hline Variables & Value \\
\hline Number of patients & 75 \\
Age, mo, median (IQR) & $21(4-35]$ \\
Weight, kg, median (IQR) & $9(4-13]$ \\
Height, cm, median (IQR) & $78(60-94]$ \\
Weight for age $z$ score, median (IQR) & $-1.25(-2.5$ to -0.41$]$ \\
Height for age $z$ score, median (IQR) & $-1.5(-2.5$ to 0.0$]$ \\
PRISM II score, median (IQR) & $6(4-9]$ \\
Mechanical ventilation, d, median (IQR) & $6(4-8]$ \\
Length of PICU stay, d, median (IQR) & $11(7-16]$ \\
Reasons for PICU admission, n & \\
Heart surgery & 34 \\
Ear-nose-tracheal surgery & 18 \\
Digestive surgery & 3 \\
Medical emergencies & 19 \\
Burns & 1 \\
FiO ${ }_{2}, \%$, median (IQR) & $35(29-44]$ \\
\hline
\end{tabular}

$\mathrm{FiO}_{2}$, fraction of inspired oxygen; PRISM, Pediatric Risk of Mortality.

${ }^{*}$ All values except for $\mathrm{n}$ are median and interquartile range.
Table III. Bias ${ }^{32}$ of predictive equations expressed in percentage at 200 and $1000 \mathrm{kcal} / \mathrm{d}$, classified according to bias at $200 \mathrm{kcal} / \mathrm{d}$. Mean bias (in percentage: mean bias / mean MEE) and limits of agreements of the Bland-Altman method (in percentage: Low/High LoA / mean MEE) ${ }^{2}$

\begin{tabular}{lccrrr}
\hline & $\begin{array}{c}\text { Bias at } \\
\mathbf{2 0 0} \mathbf{~ k c a l / d ,} \\
\text { \% }\end{array}$ & $\begin{array}{c}\text { Bias at } \\
\mathbf{1 0 0 0} \mathbf{~ k c a l / d ,} \\
\mathbf{\%}\end{array}$ & $\begin{array}{c}\text { Mean } \\
\text { bias, } \\
\text { Predictive equations }\end{array}$ & $\begin{array}{c}\text { Low } \\
\text { LoA, } \\
\mathbf{\%}\end{array}$ & $\begin{array}{c}\text { High } \\
\text { LoA, } \\
\mathbf{\%}\end{array}$ \\
\hline Tables of Talbot & -2 & -5 & -2 & -43 & 39 \\
Schofield WH & -5 & 9 & 4 & -43 & 51 \\
Henry W & -5 & 8 & 3 & -41 & 48 \\
Henry WH & 6 & 0 & 2 & -42 & 47 \\
Schofield W & -8 & 6 & 1 & -42 & 44 \\
Mehta & -10 & 0 & -3 & -21 & 15 \\
World Health Organization & -15 & 7 & -1 & -47 & 45 \\
Meyer A & -18 & -7 & -10 & -74 & 54 \\
Meyer C & 30 & -11 & 9 & -52 & 71 \\
Meyer B & 38 & -7 & 12 & -50 & 75 \\
Fleisch & 40 & -2 & 21 & -45 & 88 \\
White 1 & 40 & -15 & 11 & -96 & 120 \\
White 2 & 40 & -20 & 9 & -76 & 93 \\
Harris-Benedict infants & -40 & -33 & -33 & -64 & -2 \\
Harris-Benedict & 175 & -3 & 76 & -160 & 312 \\
\hline
\end{tabular}

of bias along the range of true REE values. These graphs clearly illustrate that the bias is generally larger for low REE values, except for the tables of Talbot. Figure 1 shows a first group of 6 equations including the equations of Mehta, Schofield, and Henry and the tables of Talbot as having the smallest bias. The equation of Mehta, which incorporates the measured $\mathrm{VCO}_{2}$ and a fixed RQ, was the most accurate. This equation slightly underestimated REE, with a bias of $-8 \%$ (95\% CI: $-17 \%,-3 \%)$ at $200 \mathrm{kcal} /$ day that gradually decreased to reach zero bias at $1000 \mathrm{kcal} /$ day. The tables of Talbot also underestimated REE, with a bias of $-1 \%(95 \% \mathrm{CI},-20 \%$ to $18 \%)$ at $200 \mathrm{kcal} /$ day that reached $-5 \%(95 \% \mathrm{CI}, 0 \%$ to $-8 \%)$ at $1000 \mathrm{kcal} / \mathrm{day}$. The 2 equations of Schofield underestimated REE up to $300 \mathrm{kcal} /$ day and overestimated REE for higher values.

A second group of equations (Figure 2), including the equations of White and Meyer specifically developed for ventilated critically ill children, showed very large biases, especially at low REE values. Except for the equation of Meyer A, specific equations for ventilated critically ill children strongly overestimated REE at low values and underestimated REE at high values. Among the tested equations, the largest bias of $+175 \%$ was observed for the equation of Harris-Benedict, at an REE of $200 \mathrm{kcal} / \mathrm{day}$. The percentage of bias and the bias plots of all equations are provided in Figures 3 and 4 (available at www.jpeds.com).

\section{Bland-Altman Mean Bias and LoA of the Predictive Equations}

The first group of 7 equations had a mean bias $<5 \%$ (Table III). The LoA of these equations were quite similar, with values around ( $-40 \%$ to $50 \%)$, except for the equation of Mehta ${ }^{13}$ that had a mean bias and LoA of $-3 \%$ (IQR, $-21 \%$ to $15 \%$ ). The tables of Talbot had a mean bias of $-2 \%$ (IQR, $-43 \%$ to $39 \%$ ). The second group of equations demonstrated larger mean biases and LoAs. 

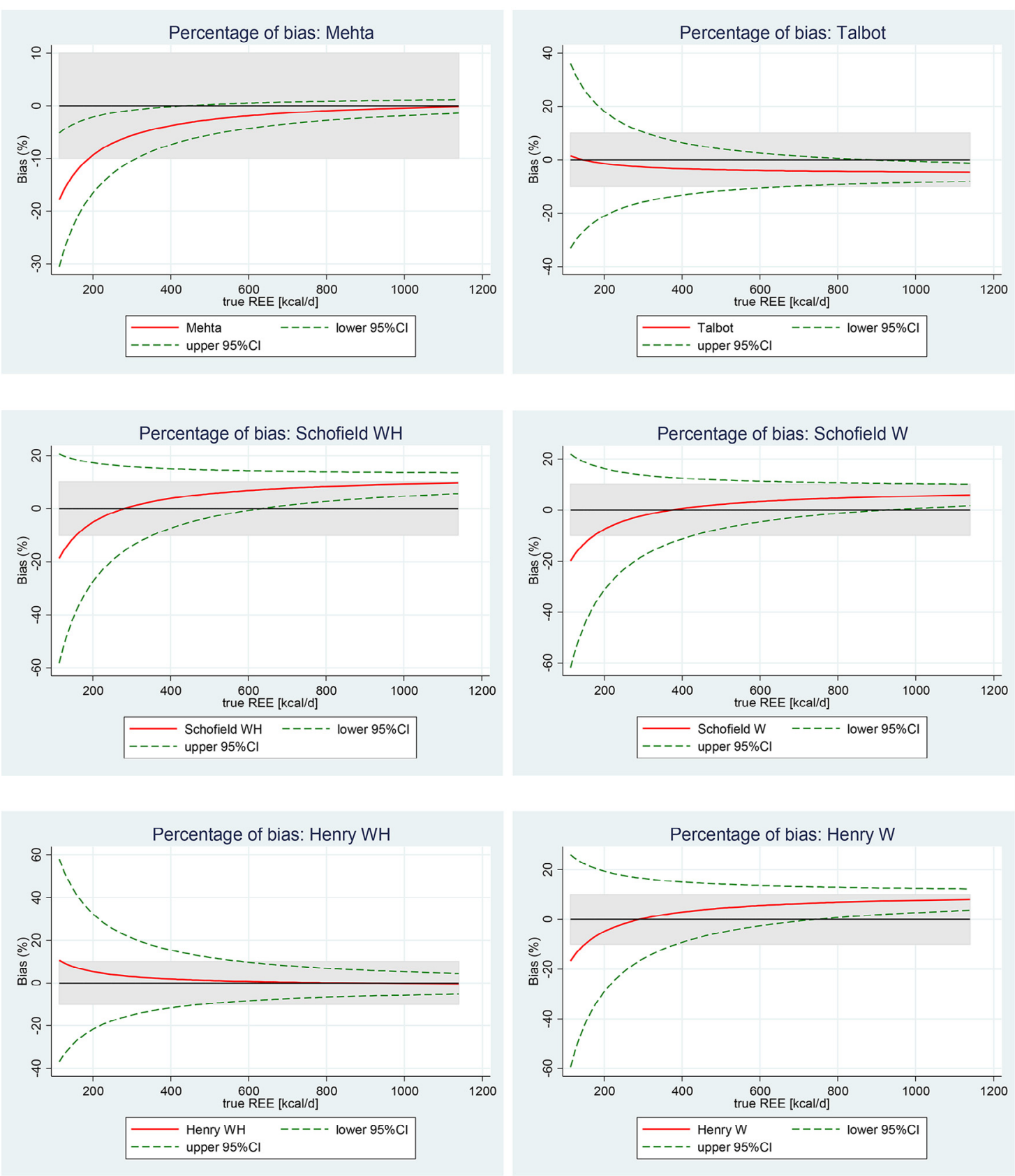

Figure 1. Percentage of bias (with $95 \% \mathrm{Cl}$ ) for the 6 equations with the smallest biases. The gray rectangle represents the cutoff of a bias of $\pm 10 \%$.

\section{Discussion}

The objective of this study was to assess the performance of 15 predictive equations for estimating REE in ventilated critically ill children. A new statistical methodology used to assess their performance ${ }^{32}$ circumvents some of the deficiencies of the Bland-Altman method. ${ }^{31-34}$ By plotting the bias (differential + proportional), this method can easily assess the performance of the equations for the entire range of REE values. Such a dynamic evaluation is not feasible with the mean bias and LoA of the Bland-Altman method. ${ }^{24}$
In the present study, both the newly developed statistical methodology ${ }^{32}$ and the Bland-Altman method demonstrated that a group of 6 equations developed for healthy children, including the tables of Talbot ${ }^{28}$ and the equations of Henry ${ }^{25}$ and Schofield, ${ }^{9}$ had the smallest biases, but they generally underestimated or overestimated REE for low values, which induces a higher risk for young children. The tables of Talbot performed very well for low and very low REE values, but this result must be carefully interpreted given the wide 95\% CI. The new equation of Mehta et $\mathrm{al}^{13}$ performed much better than the equations of Meyer ${ }^{13}$ and White ${ }^{11}$ that were developed specifically for ventilated critically ill children. 

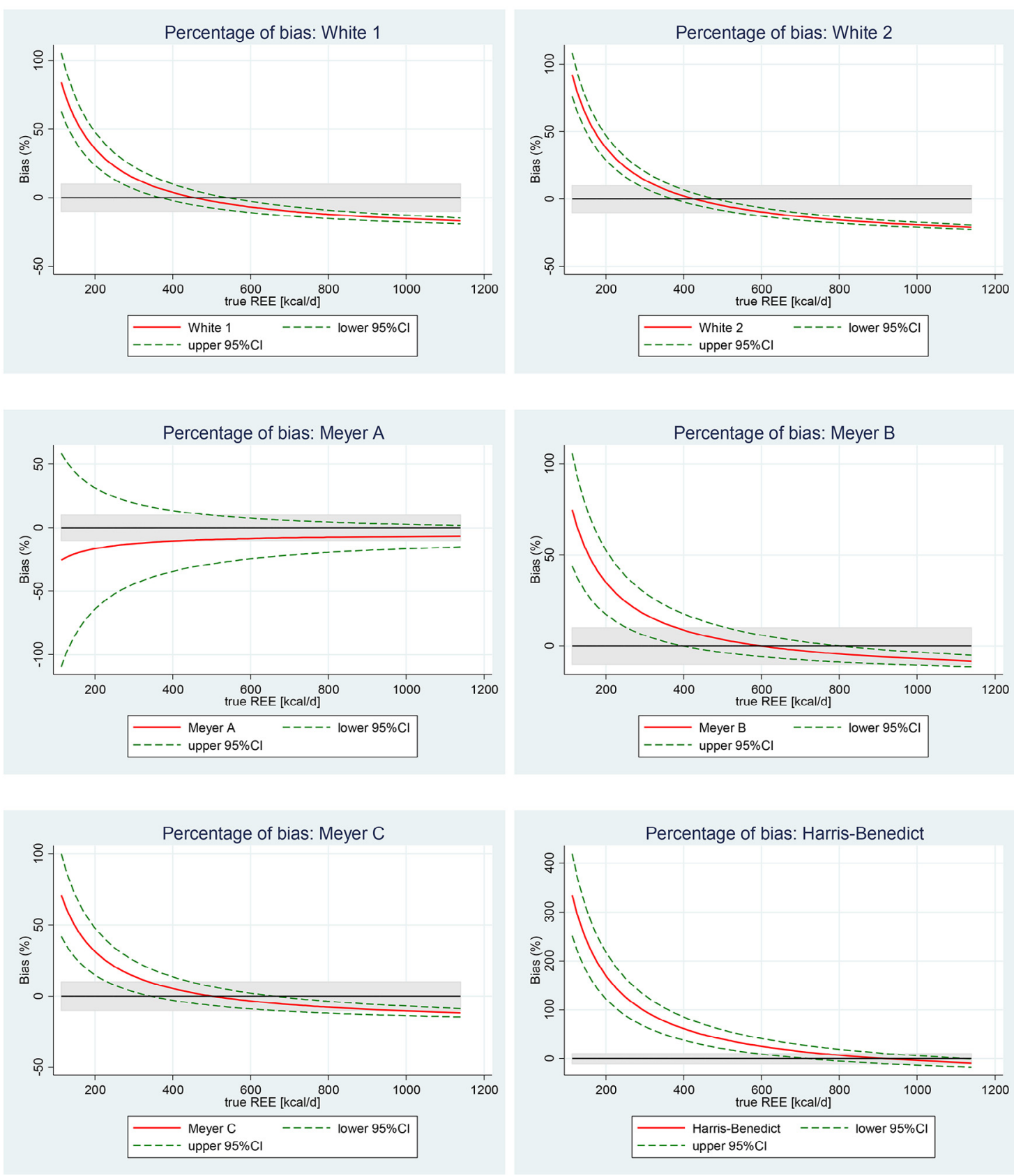

Figure 2. Percentage of bias (with $95 \% \mathrm{Cl}$ ) for the 6 equations with the largest biases. The gray rectangle represents the cutoff of a bias of $\pm 10 \%$.

Surprisingly, among the conventional predictive equations tested in this study, the tables of Talbot, ${ }^{28}$ developed in 1938 in healthy children, had the smallest bias for the tested range of REE. A few studies tested the performance of these tables using various statistical analyses, ${ }^{11,37-41}$ and similar to our results, several groups concluded that this method performed better than other equations. ${ }^{11,37,38,41}$

The 2 equations of Schofield ${ }^{9}$ have been evaluated in critically ill children by numerous authors, with controversial conclusions. ${ }^{11,12,14-17,37,38,42,43}$ However, most of those studies used the Bland-Altman method ${ }^{24}$ in their evaluation. When we used this method, the mean bias of Schofield WH (4\%) was acceptable, and the LoA showed that there may be a large discrepancy between the predicted REE and MEE values. The bias plot $^{32}$ demonstrated that this equation underestimated REE in young children and overestimated it in older children. This may explain the discordant results obtained with different age groups in the studies evaluating these equations by the Bland-Altman method. ${ }^{24}$ To our knowledge, the equations of Henry, ${ }^{25}$ also recommended by the European Food Safety Authority, ${ }^{29}$ have not yet been assessed in this population. 
The tables of Talbot ${ }^{28}$ estimate REE in calories per day for girls and boys using weight or height. These tables are easy to use in clinical practice because they do not require highly accurate anthropometric values; for instance, they provide REE for each $\mathrm{kg}$ between 3 and $20 \mathrm{~kg}$, or for each $2 \mathrm{~cm}$ between 48 and $100 \mathrm{~cm}$. The equations of Henry ${ }^{25}$ and Schofield ${ }^{9}$ estimate REE by age group (0-3, 3-10, and 10-18 years) for girls and boys using weight and eventually height. The use of age groups may diminish their performance. In clinical practice, obraining accurate weight and height may be difficult in ventilated critically ill children, especially in emergencies. In our group, three-quarters of the patients were admitted for postsurgical care with precise weight and height measurements.

The equation of Mehta ${ }^{13}$ is not a traditional predictive equation, because it requires measurement of $\mathrm{VCO}_{2}$. The LoA of the Bland-Altman method ${ }^{24}$ was the narrowest (-21\% to $\left.15 \%\right)$. The bias plot ${ }^{32}$ illustrated that this equation systematically slightly underestimated REE for low values of REE, and its bias decreased to reach zero bias at $1000 \mathrm{kcal} /$ day. The underestimation at low REE may be explained by the use of an RQ value of 0.89 in the modified Weir formula. ${ }^{22}$ In our group, the median RQ was 0.83 . In a recent report, Mouzaki et $\mathrm{al}^{18} \mathrm{ob}-$ tained 575 REE measurements by respiratory mass spectrometry in a group of 104 patients who had undergone cardiac surgery. They found that the mean difference in REE between the standard modified Weir equation ${ }^{22}$ and the simplified $\mathrm{VCO}_{2}$ Weir equation ${ }^{13}$ exceeded $10 \%$. Their mean RQ was 0.89 , and $31 \%$ of measurements had an RQ $<0.8,47 \%$ had an RQ between 0.8 and 1 , and $22 \%$ had an RQ $>1$. These authors noted wide within-subject variability for RQ. In daily practice, using the equation of Metha ${ }^{13}$ would be problematic, because this equation requires a measured $\mathrm{VCO}_{2}$. Using the Deltatrac II indirect calorimeter as the reference method, Kerklaan et $\mathrm{al}^{19} \mathrm{con}$ cluded that $\mathrm{VCO}_{2}$ measured by a ventilator (SERVO-i with a Capnostat III sensor) was sufficiently accurate only for children weighing $>15 \mathrm{~kg}$. At present, to our knowledge, only this brand of ventilator provides a $\mathrm{VCO}_{2}$ for older children. We hope that in the future a new device will be developed for all ventilators and all ages.

With a bias $\geq 40 \%$ at $200 \mathrm{kcal} / \mathrm{day}$, the equations of White 1 and $2,{ }^{11}$ Fleisch, ${ }^{26}$ and Harris-Benedict for infants and for adults $^{27}$ should not be used in the setting of young critically ill children on mechanical ventilation, sedation, and analgesia. Most of these equations had a small bias only around 600$800 \mathrm{kcal} /$ day. Their LoAs were very broad compared with those of the other equations. Using the Bland-Altman method, ${ }^{24}$ previous studies ${ }^{12,14,16,17}$ concluded that the equations of White developed specifically for ventilated ill children were highly inaccurate.

In clinical practice, if feasible, REE should be measured and not estimated in validated devices for ventilated critically ill children. The clinician must be aware that the majority of available predictive equations are strongly inaccurate. None of the tested equations fulfilled the criteria of performance for the entire range of REE between 200 and $1000 \mathrm{kcal} /$ day. The youngest children are at the greatest risk for underfeeding or overfeeding using predictive equations.
The current study has a few limitations. In our cohort, measurements were made between 150 and $1250 \mathrm{kcal} / \mathrm{d}$ and the conclusions cannot be generalized for higher values of REE. In addition, the results can be applied only to children receiving mechanical ventilation, sedation, analgesia, and enteral nutrition. Most of the children in this study were admitted for postsurgical care with quite low Pediatric Risk of Mortality II scores $^{35}$; however, the durations of mechanical ventilation and PICU stay were fairly representative of the PICU population. Furthermore, no indirect calorimetry measurements were performed in patients in a state of severe shock. Future studies in children aged $>8$ years are needed to assess the predictive equations.

Despite these limitations, this was the first study to assess the accuracy of the new predictive equations based on more than 400 indirect calorimetry measurements. Repeated indirect calorimetry measurements and the statistical methodology provided a thorough analysis of the performance of the existing predictive equations for REE between 200 and $1000 \mathrm{kcal} /$ day in ventilated critically ill children.

For optimal nutritional care in ventilated critically ill children, indirect calorimetry measurement is the best way to evaluate their energy expenditure. Presently, none of the available predictive equations is accurate for values of REE between 200 and $1000 \mathrm{kcal} /$ day.

We thank all of the children and their parents who agreed to participate in this study, as well as the medical and nursing staff of the PICU for their support.

Submitted for publication Feb 26, 2016; last revision received Nov 1, 2016 accepted Dec 21, 2016

Reprint requests: Jacques Cotting, MD, Pediatric Intensive Care Unit, University Hospital of Lausanne, Bh-05, Rue du Bugnon 46, Lausanne 1011, Switzerland. E-mail: jacques.cotting@ chuv.ch.

\section{References}

1. Mehta NM, Compher C. A.S.P.E.N. Clinical Guidelines: nutrition support of the critically ill child. JPEN J Parenter Enteral Nutr 2009;33:260-76.

2. Koletzko B, Goulet O, Hunt J, Krohn K, Shamir R. 1. Guidelines on paediatric parenteral nutrition of the European Society of Paediatric Gastroenterology, Hepatology and Nutrition (ESPGHAN) and the European Society for Clinical Nutrition and Metabolism (ESPEN), supported by the European Society of Paediatric Research (ESPR). J Pediatr Gastroenterol Nutr 2005;41(Suppl 2):S1-87.

3. van der Kuip M, de Meer K, Oosterveld MJ, Lafeber HN, Gemke RJ. Simple and accurate assessment of energy expenditure in ventilated paediatric intensive care patients. Clin Nutr 2004;23:657-63.

4. Mehta NM, Bechard LJ, Cahill N, Wang M, Day A, Duggan CP, et al. Nutritional practices and their relationship to clinical outcomes in critically ill children-an international multicenter cohort study. Crit Care Med 2012;40:2204-11.

5. Kerklaan D, Fivez T, Mehta NM, Mesotten D, van Rosmalen J, Hulst JM, et al. Worldwide survey of nutritional practices in PICUs. Pediatr Crit Care Med 2016;17:10-8.

6. Valla FV, Gaillard-Le Roux B, Ford-Chessel C, De Monte M, Tume L, Letois F, et al. A nursing survey on nutritional care practices in Frenchspeaking pediatric intensive care units: NutriRéa-Ped 2014. J Pediatr Gastroenterol Nutr 2016;62:174-9.

7. Takala J, Keinänen $O$, Väisänen $P$, Kari A. Measurement of gas exchange in intensive care: laboratory and clinical validation of a new device. Crit Care Med 1989;17:1041-7. 
8. Tissot S, Delafosse B, Bertrand O, Bouffard Y, Viale JP, Annat G Clinical validation of the Deltatrac monitoring system in mechanically ventilated patients. Intensive Care Med 1995;21:149-53.

9. Schofield WN. Predicting basal metabolic rate, new standards and review of previous work. Hum Nutr Clin Nutr 1985;39 Suppl 1:5-41.

10. $\mathrm{FAO} / \mathrm{WHO} / \mathrm{UNU}$. Energy and protein requirements: report of a joint $\mathrm{FAO} /$ WHO/UNU expert consultation. Geneva: World Health Organization; 1985.

11. White MS, Shepherd RW, McEniery JA. Energy expenditure in 100 ventilated, critically ill children: improving the accuracy of predictive equations. Crit Care Med 2000;28:2307-12.

12. Meyer R, Kulinskaya E, Briassoulis G, Taylor RM, Cooper M, Pathan N, et al. The challenge of developing a new predictive formula to estimate energy requirements in ventilated critically ill children. Nutr Clin Pract 2012;27:669-76.

13. Mehta NM, Smallwood CD, Joosten KF, Hulst JM, Tasker RC, Duggan CP. Accuracy of a simplified equation for energy expenditure based on bedside volumetric carbon dioxide elimination measurement-a twocenter study. Clin Nutr 2015;34:151-5.

14. Taylor RM, Cheeseman P, Preedy V, Baker AJ, Grimble G. Can energy expenditure be predicted in critically ill children? Pediatr Crit Care Med 2003;4:176-80.

15. Havalad S, Quaid MA, Sapiega V. Energy expenditure in children with severe head injury: lack of agreement between measured and estimated energy expenditure. Nutr Clin Pract 2006;21:175-81.

16. Framson CM, LeLeiko NS, Dallal GE, Roubenoff R, Snelling LK, Dwyer JT. Energy expenditure in critically ill children. Pediatr Crit Care Med 2007;8:264-7.

17. De Wit B, Meyer R, Desai A, Macrae D, Pathan N. Challenge of predicting resting energy expenditure in children undergoing surgery for congenital heart disease. Pediatr Crit Care Med 2010;11:496-501.

18. Mouzaki M, Schwartz SM, Mtaweh H, La Rotta G, Mah K, Herridge J, et al. Can Vco2-based estimates of resting energy expenditure replace the need for indirect calorimetry in critically ill children? JPEN J Parenter Enteral Nutr 2016. doi: 10.1177/0148607115627143. [Epub ahead of print].

19. Kerklaan D, Augustus ME, Hulst JM, van Rosmalen J, Verbruggen SC, Joosten KF. Validation of ventilator-derived VCO2 measurements to determine energy expenditure in ventilated critically ill children. Clin Nutr 2016. doi: 10.1016/j.clnu.2016.01.001. [Epub ahead of print].

20. Jotterand Chaparro C, Laure Depeyre J, Longchamp D, Perez MH, Taffé $P$, Cotting J. How much protein and energy are needed to equilibrate nitrogen and energy balances in ventilated critically ill children? Clin Nutr 2016;35:460-7.

21. Ward MW, Owens CW, Rennie MJ. Nitrogen estimation in biological samples by use of chemiluminescence. Clin Chem 1980;26:1336-9.

22. Weir JB. New methods for calculating metabolic rate with special reference to protein metabolism. J Physiol 1949;109:1-9.

23. Smyrnios NA, Curley FJ, Shaker KG. Accuracy of 30-minute indirect calorimetry studies in predicting 24-hour energy expenditure in mechanically ventilated, critically ill patients. JPEN J Parenter Enteral Nutr 1997;21:168-74.
24. Bland JM, Altman DG. Statistical methods for assessing agreement between two methods of clinical measurement. Lancet 1986;1:307-10.

25. Henry CJ. Basal metabolic rate studies in humans: measurement and development of new equations. Public Health Nutr 2005;8:1133-52.

26. Fleisch A. Basal metabolism standard and its determination with the "metabocalculator". Helv Med Acta 1951;18:23-44.

27. Harris JA, Benedict GF. A biometric study of basal metabolism in man. Washington (DC): Carnegie Institution of Washington; 1919.

28. Talbot FB. Basal metabolism standards for children. Am J Dis Child 1938;55:455-9.

29. EFSA Panel on Dietetic Products, Nutrition and Allergies. Scientific opinion on dietary reference values for energy. EFSA J 2013;11:3005.

30. Bland JM, Altman DG. Measuring agreement in method comparison studies. Stat Methods Med Res 1999;8:135-60.

31. Ludbrook J. Confidence in Altman-Bland plots: a critical review of the method of differences. Clin Exp Pharmacol Physiol 2010;37:143-9.

32. Taffé P. Effective plots to assess bias and precision in method comparison studies. Stat Methods Med Res 2016. doi:10.1177/0962280216666667. [Epub ahead of print].

33. Ludbrook J. Linear regression analysis for comparing two measurers or methods of measurement: but which regression? Clin Exp Pharmacol Physiol 2010;37:692-9.

34. Carstensen B, Simpson J, Gurrin LC. Statistical models for assessing agreement in method comparison studies with replicate measurements. Int J Biostat 2008;4:Article 16.

35. Pollack MM, Ruttimann UE, Getson PR. Pediatric risk of mortality (PRISM) score. Crit Care Med 1988;16:1110-6.

36. WHO Multicentre Growth Reference Study Group. WHO Child Growth Standards based on length/height, weight and age. Acta Paediatr Suppl 2006;450:76-85.

37. Briassoulis G, Venkataraman S, Thompson AE. Energy expenditure in critically ill children. Crit Care Med 2000;28:1166-72.

38. Hardy CM, Dwyer J, Snelling LK, Dallal GE, Adelson JW. Pitfalls in predicting resting energy requirements in critically ill children: a comparison of predictive methods to indirect calorimetry. Nutr Clin Pract 2002;17:182-9.

39. Chwals WJ, Lally KP, Woolley MM, Mahour GH. Measured energy expenditure in critically ill infants and young children. J Surg Res 1988;44:467-72.

40. Coss-Bu JA, Jefferson LS, Walding D, David Y, Smith EO, Klish WJ. Resting energy expenditure in children in a pediatric intensive care unit: comparison of Harris-Benedict and Talbot predictions with indirect calorimetry values. Am J Clin Nutr 1998;67:74-80.

41. Gebara BM, Gelmini M, Sarnaik A. Oxygen consumption, energy expenditure, and substrate utilization after cardiac surgery in children. Crit Care Med 1992;20:1550-4.

42. Verhoeven JJ, Hazelzet JA, van der Voort E, Joosten KF. Comparison of measured and predicted energy expenditure in mechanically ventilated children. Intensive Care Med 1998;24:464-8.

43. Vazquez Martinez JL, Martinez-Romillo PD, Diez Sebastian J, Ruza Tarrio F. Predicted versus measured energy expenditure by continuous, online indirect calorimetry in ventilated, critically ill children during the early postinjury period. Pediatr Crit Care Med 2004;5:19-27. 

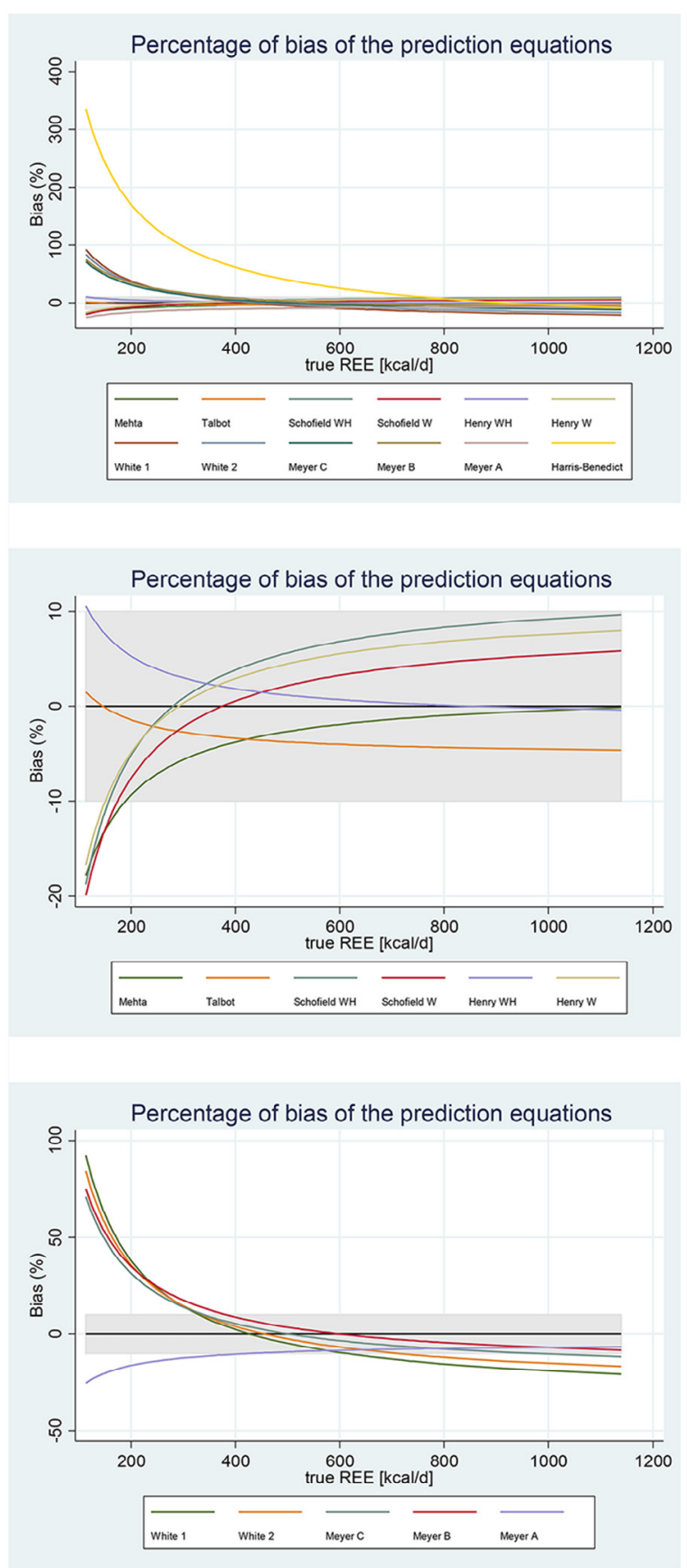

Figure 3. Percentage of bias of the 2 groups of equations with the smallest and largest biases. The gray rectangle represents the cutoff of a bias of $\pm 10 \%$. 

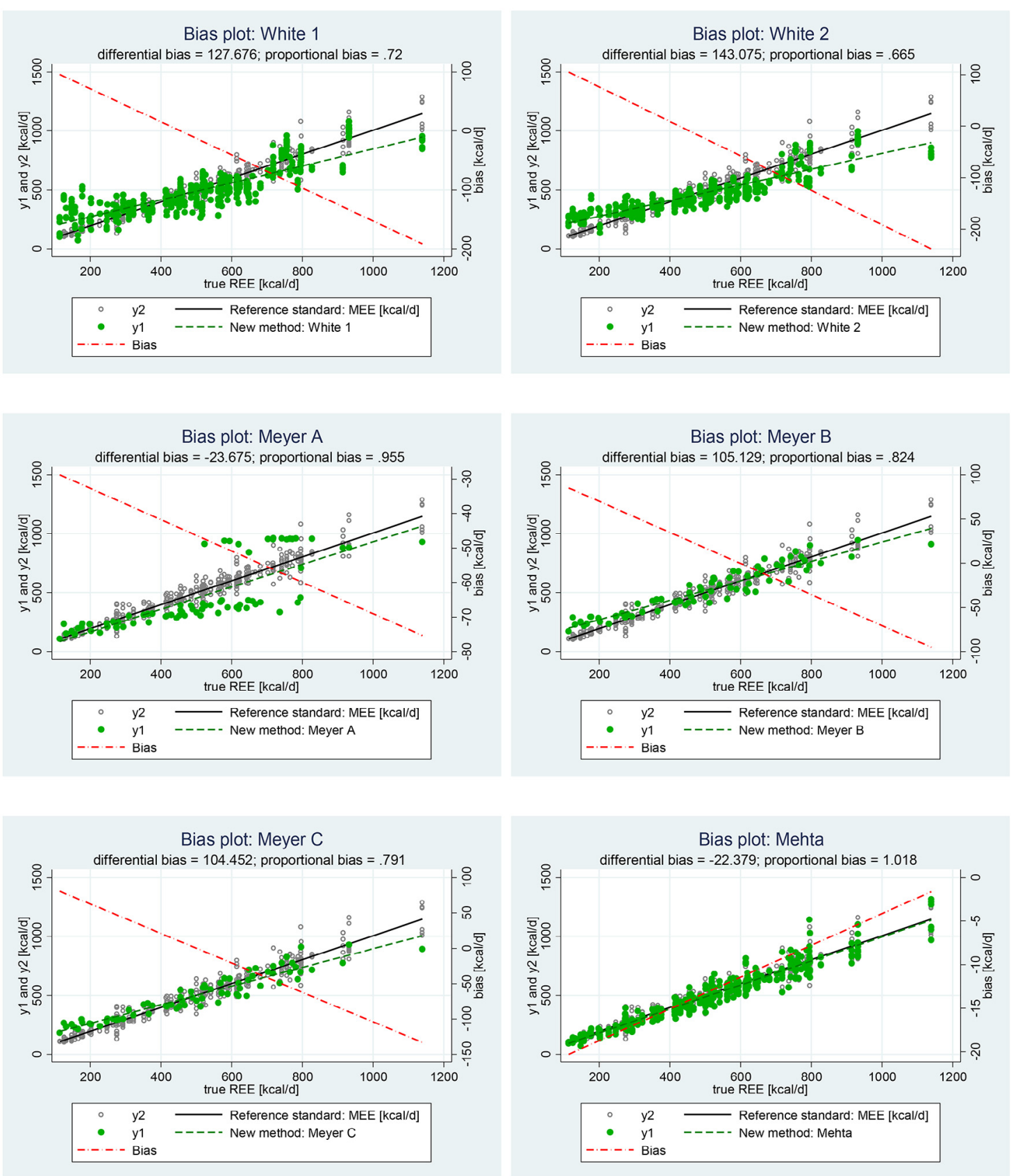

Figure 4. Bias plots ${ }^{32}$ for the 15 predictive equations. The left $y$-axis of the bias plot shows the values of MEE ( $y 2$; black circles) and values of predicted REE ( $y 1$; green circles). The $x$-axis represents the best prediction of the true (unknown) value of REE. Black regression line for MEE and dotted green line for predicted REE allow visual comparison of the 2 methods. On top of the plot, differential and proportional biases are provided. Using the right $y$-axis, the red dotted line shows the bias (differential + proportional) for the range of REE values. Negative values of the red dotted line represent underestimation of REE by the equation, and positive values represent overestimation. 

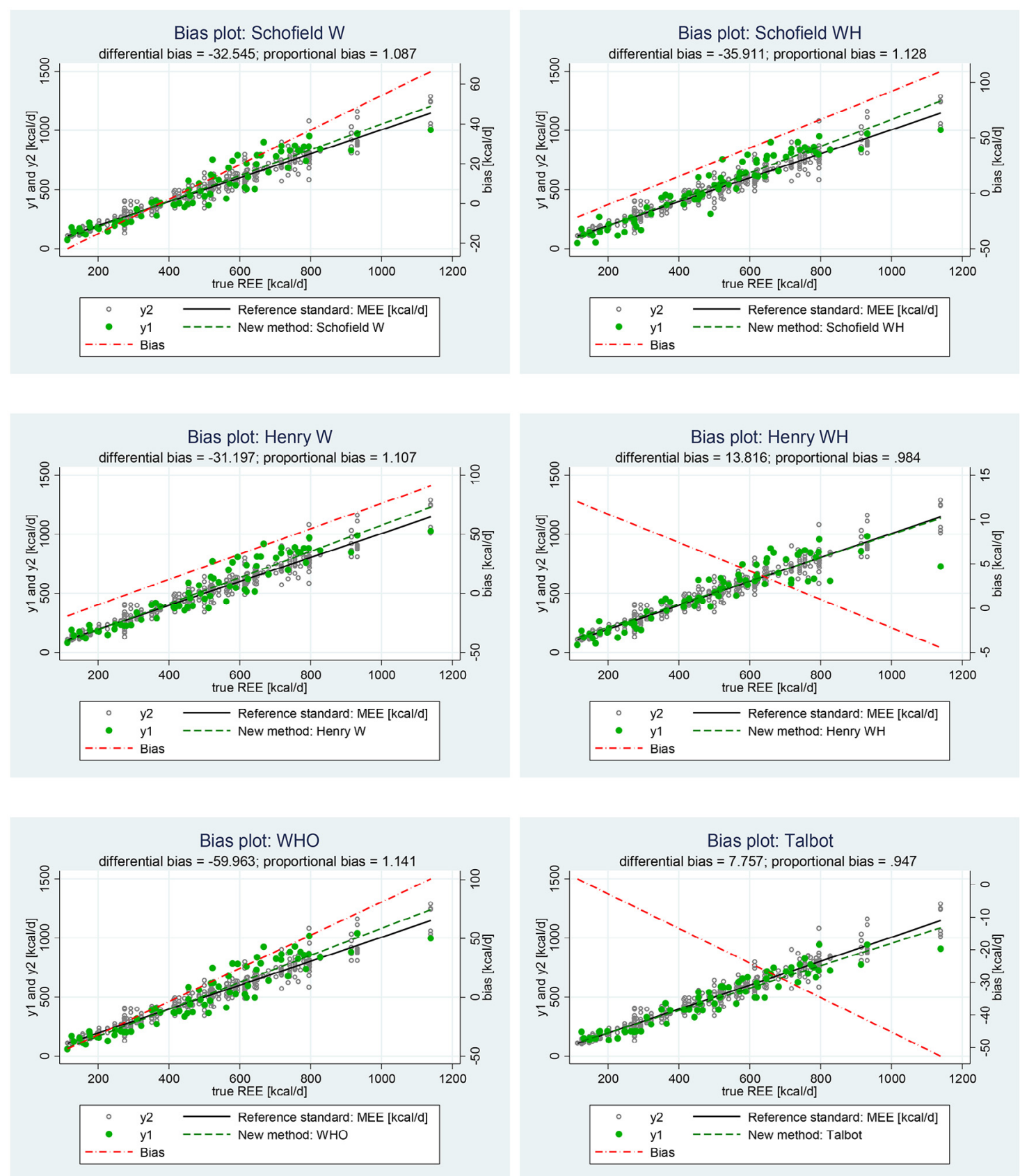

Fig. 4.Continued 

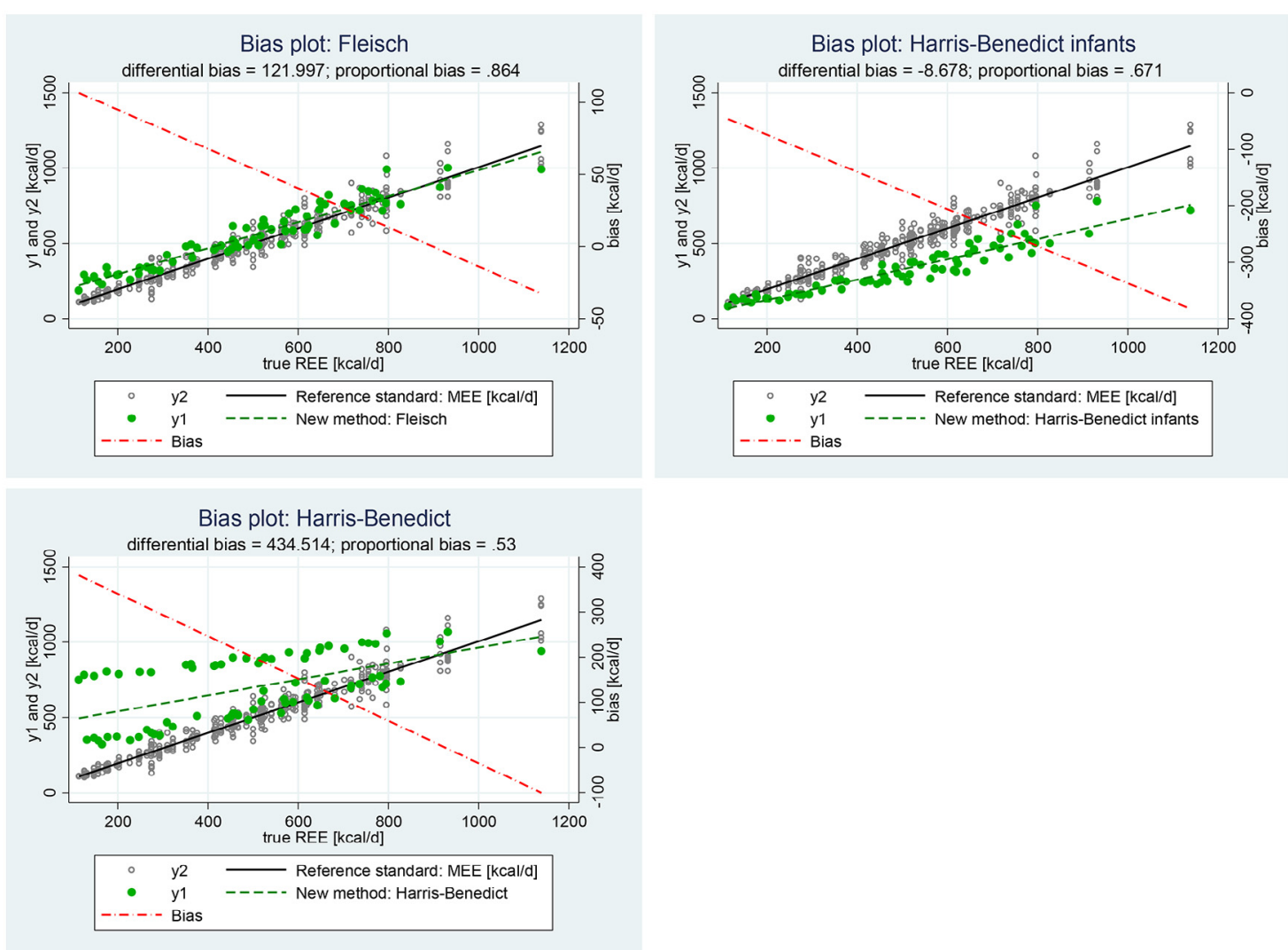

Fig. 4.Continued 

Table I. Predictive equations specifically developed to es-
timate REE in ventilated critically ill children and the
equations of Schofield for healthy children

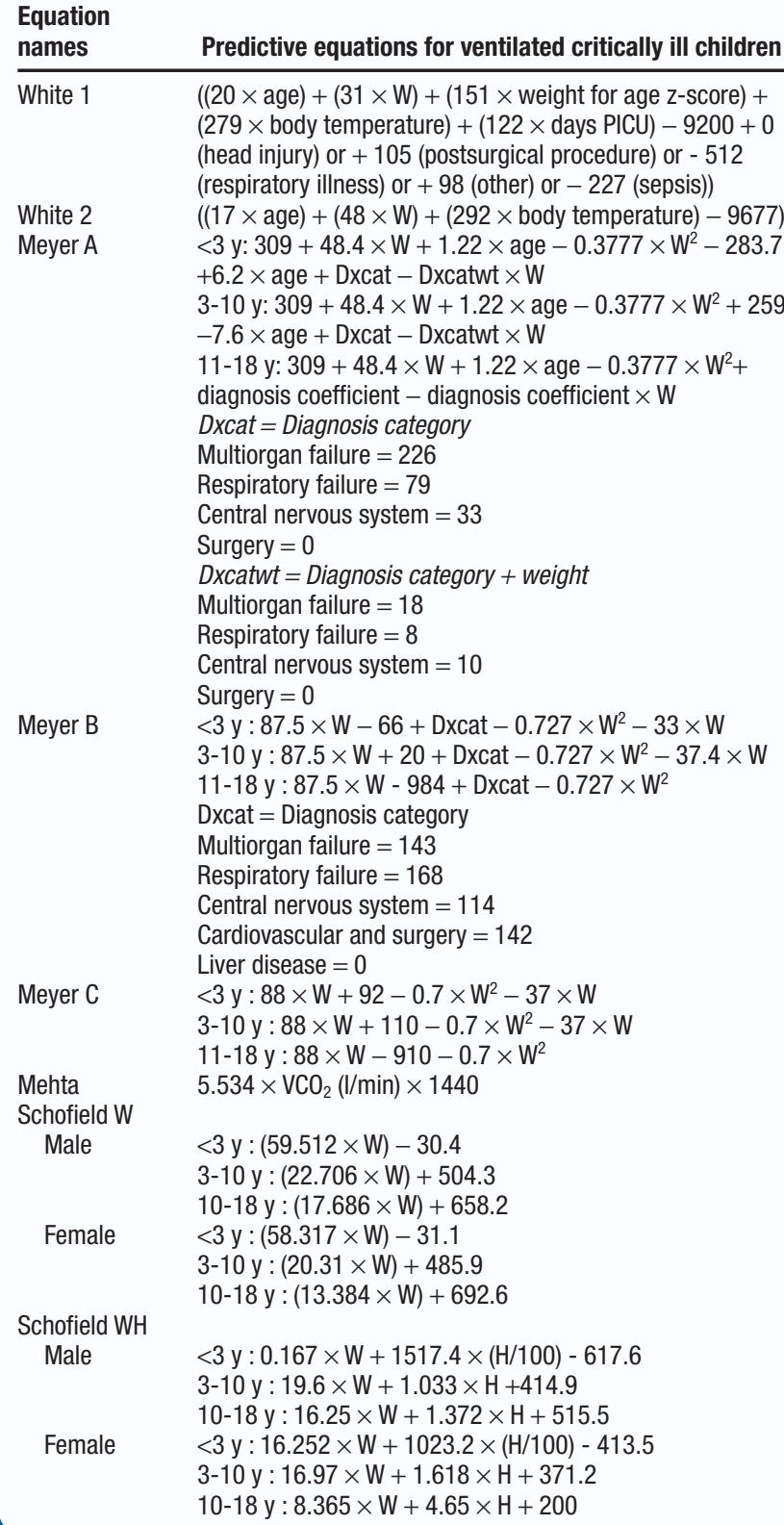

